\title{
Letters
}

\section{Laterality and incidence of adhesive capsulitis of the shoulder and plantar fasciitis among rural Saudis in the Jeddah zone}

SIR, In western medical publications adhesive capsulitis ('frozen shoulder', 'shoulder-hand syndrome') is supposedly commoner on the left side, ' perhaps related to the finding that in an appreciable number of cases of adhesive capsulitis there is a preceding episode of a silent or overt cardiac infarct. The laterality and incidence of this condition and of plantar fasciitis were investigated among rural Saudis in a newly opened government general hospital in the Jeddah zone to see if the findings correlated with those in the West.

A significant right sided preponderance in clinical symptoms of adhesive capsulitis ${ }^{2}{ }^{3}$ and a significant left sided preponderance of plantar fasciitis was found among 6000 rural Saudis in the Jeddah zone, seen in the orthopaedic outpatients clinic in the first 18 months of the newly opened hospital. There were 375 presentations of clinical adhesive capsulitis from 369 patients (201 male, 168 female) with the complaint, an incidence of $6.15 \%$ $(369 / 6000)$. The age range was $17-75$ years, with an average age for the men of 43 and for the women of 42 . The disorder was bilateral in six patients (three men, three women), right sided in 216 , and left sided in 147-a significant right sided preponderance. Over the same period there were 84 presentations of clinical plantar fasciitis from 78 patients (63 male, 15 female), an incidence of $1.3 \% .^{4}$ Symptoms were left sided in 48 instances, right sided in 18 , and bilateral in 12 -a significant left sided preponderance. The age range was 28-60 years, with an average age for the men of 35 and for the women of 43 . For those with bilateral involvement the average age was also 43 years.

No ready explanation was found for the laterality observed in these conditions. Perhaps social customs are implicated. Further studies seem to be warranted.

King Fahad Specialist Hospital,

W C R AGUNWA Orthopaedic Department,

Medinah,

Saudi Arabia

\section{References}

1 McRac R. Clinical orthopaedic examination. Edinburgh. London and New York: Churchill Livingstone, 1976: 22-3.

2 Kessel L, Watson M. The painful arc syndrome: clinical classification as a guide to management. J Bone Joint Surg $[\mathrm{Br}]$ 1977; 59: 166-72.
3 Booth R E Jr, Marvel J P Jr. Differential diagnosis of shoulder pain. Orthop Clin North Am 1975; 6: 353-79.

4 Helfet A J. Gruebel Lee D M. Disorders of the foot. Philadelphia: Lippincott. 1980: 150-1.

\section{Low incidence of osteoarthrosis of the hips in contrast with osteoarthrosis of the knees among rural Saudis: Why?}

SIR, There was a striking absence of clinically symptomatic osteoarthrosis of the hips among rural Saudis seen in the orthopaedic outpatient clinic in the first 18 months of a newly opened Ministry of Health Adhum general hospital in the Jeddah zone. The picture was entirely different for symptoms from clinical and radiological degenerative changes involving the knees. Of the 6000 patients seen during the period, there were only 15 presentations from 12 patients (six male, six female) with complaints and radiological evidence of osteoarthritis of the hip, an incidence of $0 \cdot 2 \%(12 / 6000)$. The complaints were right sided in six instances, left sided in three, and bilateral in three patients (all male). The age range was 50-65 years, with an average age for the men of 55 and for the women of 60 . Very few of the degenerative hip changes were advanced and these were all secondary to old fractures around the hip joint. ${ }^{1}$

During the same period there were 579 presentations from 375 patients (264 men, 111 women) with complaints and radiological features of osteoarthritis of the knees, an incidence of $6 \cdot 25 \%$. The complaints were bilateral in 132 men and 69 women, right sided only in 93 instances, and left sided only in 81 . The presenting symptoms were patellofemoral in $82 \%$ of the patients. The age range of patients with knee complaints was $15-80$ years, with an average age for the men of 54 and for the women of 48 . For patients with bilateral knee complaints the average age for the men was 61 and for the women 47 years. Overall, the degenerative changes in the knees were advanced in $43.75 \%$ of the patients seen.

Pathological and roentgenographic evidence of osteoarthritis (osteoarthrosis) is not rare as early as the third decade of life. ${ }^{2}{ }^{3}$ Racial differences in prevalence and distribution of affected joints, however, may be related to differences in occupation, lifestyle, and predisposing genetic factors. The low incidence of osteoarthritis of the hip in the Chinese as compared with whites is supposedly related to protection of the joint by the more complete range of motion associated with frequent squatting. ${ }^{4}$ The possibility that praying postures, or something similar to the Chinese factor in the rural Saudis seen in the study, results in their enviable low incidence of osteoarthritis of 
the hip, is open to question. Further studies are also necessary to explain the high incidence of patellofemoral degenerative changes and complaints observed.

King Fahad Specialist Hospital,

W C R AGUNWA Orthopaedic Department,

Medinah,

Saudi Arabia

\section{References}

1 Solomon L. Patterns of osteoarthritis of the hip. J Bone Joint Surg /Brl 1976; 58: 176-83.

2 Radin E L. The physiology and degeneration of joints. Semin Arthritis Rheum 1973; 2: 245-57.

3 Radin E L. Mechanical aspects of osteoarthritis. Bull Rheum Dis 1976; 26: 862-5.

4 Hoagland F J, Yau A G M C. Wong W L. Osteoarthritis of the hip and other joints in Southern Chinese in Hong Kong. $J$ Bone Joint Surg [Am] 1973; 55: 545-57.

\section{Corticosteroid dosage for temporal arteritis}

SIR, I was interested to read the paper by Delecoeuillerie $e t$ al on polymyalgia rheumatica and temporal arteritis. ' It would appear from their results that most patients with temporal arteritis can be treated with low doses of corticosteroid-that is, no more than $20 \mathrm{mg} / \mathrm{d}$ of prednisone. They treated 25 patients with $10-20 \mathrm{mg} / \mathrm{d}$ of prednisone, and these patients did not experience any more temporal arteritis complications and had significantly less corticosteroid related adverse effects than 53 patients treated with higher doses. In view of their concern about? corticosteroid side effects they suggested that controlled $\vec{F}$ trials are needed to evaluate the results of treatment with $\stackrel{\text { ? }}{+}$ low doses of corticosteroid for both polymyalgia rheumatica? and temporal arteritis.

Although there is no evidence to suggest that high doses $\overline{\bar{\omega}}$ of corticosteroid given at the time of arteritic crises such as blindness in temporal arteritis make any difference to the outcome, it is customary to treat patients with temporales arteritis with high doses of corticosteroid from the outset. $\overrightarrow{0}$ on the grounds that this will prevent complications such as blindness occurring. Only when temporal arteritis is under $\vec{\omega}$ control is the dose of corticosteroid subsequently lowered. If it could be shown that certain patients with polymyalgia rheumatica and temporal arteritis will develop these: arteritic crises irrespective of the dose of prednisone usedọ then obviously there would be no need for high doses of corticosteroid. At the moment there is no way of identifyinge that small group of patients from the majority who suffer $\vec{\cdot}$ no serious arteritic complications. To have a trial in which patients with temporal arteritis are kept on low doses of corticosteroid (no more than $20 \mathrm{mg} / \mathrm{d}$ of prednisone) could raise serious ethical and medicolegal questions.

Department of Rheumatology, ANTHONY J RICHARDS Worthing Hospital,

Park Avenue,

Worthing,

West Sussex BN11 2DH

\section{Reference}

1 Delecoeuillerie G, Joly P, Cohen de Lara A, Paolaggi J B. @ Polymyalgia rheumatica and temporal arteritis: a retrospective $\overrightarrow{\vec{C}}$ analysis of prognostic features and different corticosteroid $\underline{9}$ regimens (11 year survey of 210 patients). Ann Rheum Dis 1988; 47: 733-9. 